Virginia Commonwealth University VCU Scholars Compass

2007

\title{
Peginterferon Alfa-2a and Ribavirin for 16 or 24 Weeks in HCV Genotype 2 or 3
}

Mitchell L. Shiffman

Virginia Commonwealth University

Fredy Suter

Ospedali Riuniti

Bruce R. Bacon

St Louis University

See next page for additional authors

Follow this and additional works at: http://scholarscompass.vcu.edu/vcuhealth_pubs

Part of the Medicine and Health Sciences Commons

From The New England Journal of Medicine, Shiffman, M. L., Suter, F., Bacon, B. R. et al., Peginterferon Alfa-2a and Ribavirin for 16 or 24 Weeks in HCV Genotype 2 or 3, Vol. 357, Page 124, Copyright (C) 2007 Massachusetts Medical Society. Reprinted with permission.

\section{Downloaded from}

http://scholarscompass.vcu.edu/vcuhealth_pubs/17

This Article is brought to you for free and open access by the VCU Health at VCU Scholars Compass. It has been accepted for inclusion in VCU Health Publications by an authorized administrator of VCU Scholars Compass. For more information, please contact libcompass@vcu.edu. 


\section{Authors}

Mitchell L. Shiffman, Fredy Suter, Bruce R. Bacon, David Nelson, Hugh Harley, Richard Sola, Stephen D. Shafran, Karl Barange, Amy Lin, Ash Soman, and Stefan Zeuzem 


\title{
Peginterferon Alfa-2a and Ribavirin for 16 or 24 Weeks in HCV Genotype 2 or 3
}

\author{
Mitchell L. Shiffman, M.D., Fredy Suter, M.D., Bruce R. Bacon, M.D., \\ David Nelson, M.D., Hugh Harley, M.B., B.S., Ricard Solá, M.D., \\ Stephen D. Shafran, M.D., Karl Barange, M.D., Amy Lin, M.S., Ash Soman, M.B., B.S., \\ and Stefan Zeuzem, M.D., for the ACCELERATE Investigators*
}

ABSTRACT

From the Virginia Commonwealth University Medical Center, Richmond (M.L.S.); Ospedali Riuniti, Bergamo, Italy (F.S.); Saint Louis University, St. Louis (B.R.B.); University of Florida, Gainesville (D.N.); Royal Adelaide Hospital, Adelaide, Australia (H.H.); Universitat Autònoma de Barcelona, Barcelona (R.S.); University of Alberta Hospital, Edmonton, Canada (S.D.S.); Hôpital Purpan, Toulouse, France (K.B.); Roche, Nutley, NJ (A.L.); Roche, Welwyn, United Kingdom (A.S.); and Saarland University Hospital, Homburg/Saar, Germany (S.Z.). Address reprint requests to Dr. Shiffman at the Liver Transplant Program, Virginia Commonwealth University Medical Center, 1251 E. Marshall St., Box 663, Richmond, VA 23298, or at mshiffma@vcu.edu.

*The investigators who participated in the ACCELERATE trial are listed in the Appendix.

N Engl J Med 2007;357:124-34.

Copyright $(2007$ Massachusetts Medical Society.

\section{BACKGROUND}

Patients infected with hepatitis C virus (HCV) genotype 2 or 3 have sustained virologic response rates of approximately $80 \%$ after receiving treatment with peginterferon and ribavirin for 24 weeks. We conducted a large, randomized, multinational, noninferiority trial to determine whether similar efficacy could be achieved with only 16 weeks of treatment with peginterferon alfa-2a and ribavirin.

\section{METHODS}

We randomly assigned 1469 patients with HCV genotype 2 or 3 to receive $180 \mu \mathrm{g}$ of peginterferon alfa-2a weekly, plus $800 \mathrm{mg}$ of ribavirin daily, for either 16 or 24 weeks. A sustained virologic response was defined as an undetectable serum HCV RNA level ( $<50$ IU per milliliter) 24 weeks after the end of treatment.

\section{RESULTS}

The study failed to demonstrate that the 16-week regimen was noninferior to the 24-week regimen. The sustained virologic response rate was significantly lower in patients treated for 16 weeks than in patients treated for 24 weeks $(62 \%$ vs. $70 \%$; odds ratio for 16 weeks vs. 24 weeks, 0.67 ; $95 \%$ confidence interval, 0.54 to 0.84 ; $\mathrm{P}<0.001$ ). In addition, the rate of relapse (a detectable HCV RNA level during follow-up in patients who had undetectable HCV RNA at the end of treatment) was significantly greater in the 16 -week group $(31 \%$, vs. $18 \%$ in the 24 -week group; $\mathrm{P}<0.001)$. The sustained virologic response rates in patients with a pretreatment serum HCV RNA level of 400,000 IU per milliliter or less was $82 \%$ with the 16 -week regimen and $81 \%$ with the $24-w e e k$ regimen. Among patients with a rapid virologic response (an undetectable HCV RNA level by week 4), sustained virologic response rates were $79 \%$ in the 16 -week group and $85 \%$ in the 24 -week group $(\mathrm{P}=0.02)$.

\section{CONCLUSIONS}

Treatment with peginterferon and ribavirin for 16 weeks in patients infected with HCV genotype 2 or 3 results in a lower overall sustained virologic response rate than treatment with the standard 24-week regimen. (ClinicalTrials.gov number, NCT00077636.) 
T HE CURRENTLY RECOMMENDED TREATment for patients infected with hepatitis $\mathrm{C}$ virus (HCV) genotype 2 or 3 is peginterferon, plus $800 \mathrm{mg}$ of ribavirin daily, for 24 weeks. $^{1}$ Approximately $80 \%$ of patients have a sustained virologic response with this regimen. ${ }^{2,3}$ This high response rate has prompted studies of shorter treatment durations. Sustained virologic response rates of 80 to $85 \%$ were observed with just 12 to 16 weeks of treatment in patients whose HCV RNA levels became undetectable within 4 weeks after commencing treatment. ${ }^{4-7}$ These results suggest that patients with HCV genotype 2 or 3 who have a rapid virologic response (an undetectable HCV RNA level by week 4) could be treated for less than 24 weeks. However, confirmation is needed before a shortened treatment period can be widely recommended for patients with $\mathrm{HCV}$ genotype 2 or $3 .^{8}$ In our large, randomized, multinational study, we aimed to determine whether similar efficacies could be achieved with 16 and 24 weeks of treatment with peginterferon alfa-2a plus ribavirin in patients infected with HCV genotype 2 or 3.

\section{METHODS}

The trial was designed by the sponsor and the principal academic investigators. The data were collected by Covance Central Laboratory Services and were managed by the sponsor and the academic investigators. The sponsor performed the statistical analysis. The academic investigators were responsible for the decision to publish the results and had unrestricted access to the data. An academic author wrote or edited all sections of the manuscript. One academic author (Dr. Shiffman) and one industry author (Ms. Lin) vouch for the completeness and accuracy of the data.

\section{SELECTION OF PATIENTS}

Eligible patients were those who were 18 years of age or older, were infected with HCV genotype 2 or 3 (as determined with the use of the INNO-LiPA assay, Innogenetics), and had a quantifiable serum HCV RNA level (>600 IU per milliliter), an elevated serum alanine transaminase level, and findings on liver biopsy consistent with chronic HCV infection. Patients were ineligible if they had other liver diseases, were infected with the human immunodeficiency virus, had hepatocellular carcinoma, had severe depression or another se- vere psychiatric disease, had clinically significant cardiovascular or renal disease, had an uncontrolled seizure disorder, had severe retinopathy, or had previously received interferon or ribavirin. Patients with cirrhosis had to have a Child-Pugh score of less than 7 to be eligible.

\section{STUDY DESIGN}

The study was conducted at 132 centers worldwide. All sites received approval from an appropriate institutional review board. The first patient was enrolled in November 2003, and the last patient completed follow-up in September 2005. Each patient provided written informed consent. Patients were randomly assigned, in a 1:1 ratio, to receive 16 or 24 weeks of treatment with subcutaneous peginterferon alfa-2a (Pegasys, Roche), $180 \mu \mathrm{g}$ once weekly, plus oral ribavirin (Copegus, Roche), $400 \mathrm{mg}$ twice daily. The treatment period was followed by a 24-week observation period. Patients were randomly assigned in blocks of four and were stratified according to HCV genotype and country of residence. Assignment to treatment duration was centralized, with the sponsor, investigators, and patients unaware of the assignment. Treatment duration was double-blinded until week 16 , at which time investigators were informed by telephone of their patients' assignments.

\section{EFFICACY ASSESSMENTS}

Serum HCV RNA levels were measured with the use of a qualitative polymerase-chain-reaction assay (Cobas Amplicor HCV Test, version 2.0; detection limit, 50 IU per milliliter) at weeks 4, 12, and 16 or 24 during the treatment phase and at weeks 12 and 24 of follow-up. The primary end point was sustained virologic response, defined as an undetectable serum HCV RNA level at 24 weeks after the end of treatment. A rapid virologic response was defined as an undetectable serum HCV RNA level by week 4 of treatment. Virologic relapse was defined as a detectable HCV RNA level during follow-up in patients who had had undetectable HCV RNA at the end of treatment.

\section{SAFETY ASSESSMENTS}

Safety was assessed by means of physical examinations and laboratory tests at weeks 2, 4, 8, 12, and 16 in both groups and at weeks 20 and 24 in the 24-week group (all during the treatment period), as well as at weeks 4, 12, and 24 of the follow-up period in both groups. Stepwise reduc- 


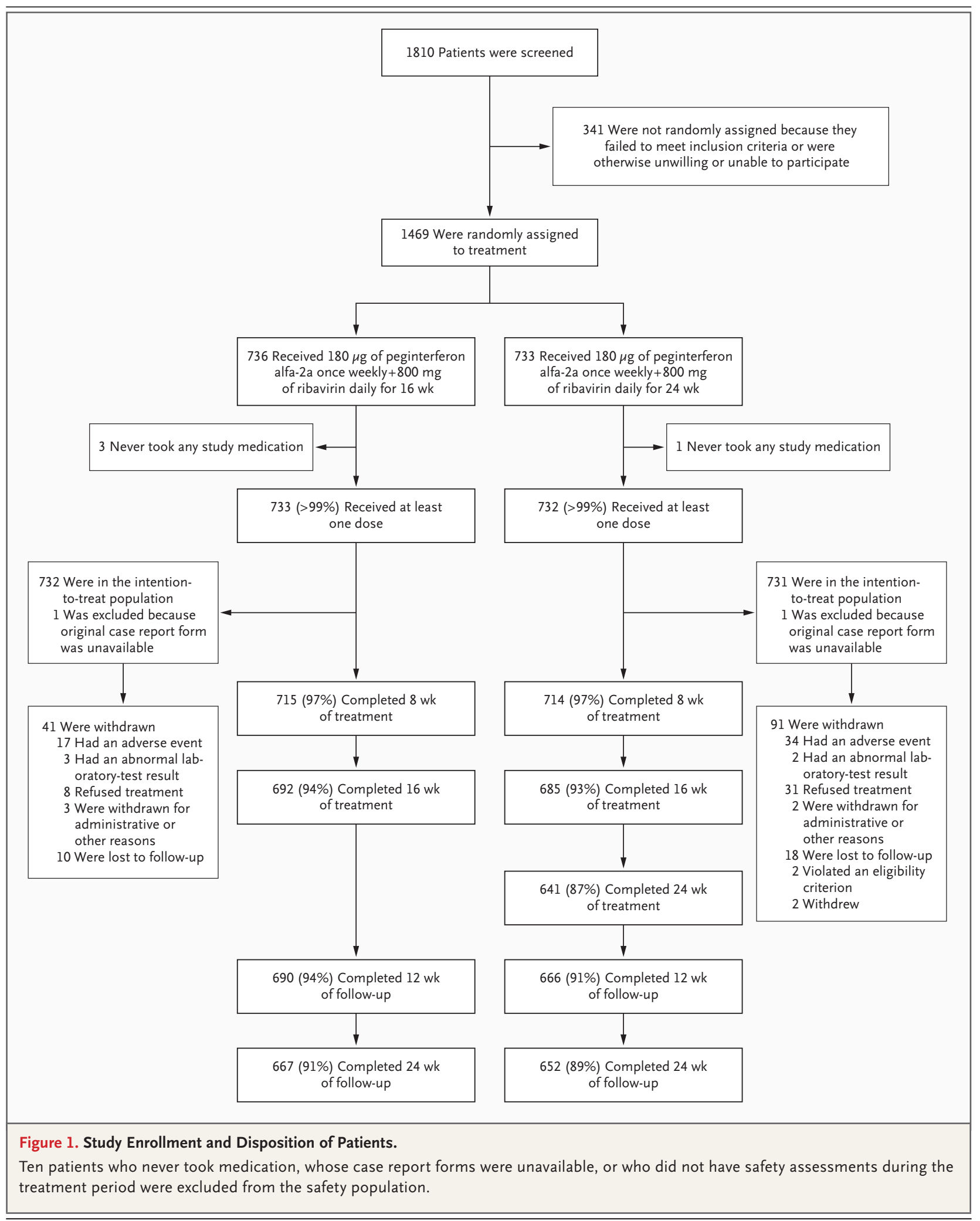




\begin{tabular}{|c|c|c|c|c|c|c|}
\hline \multirow[t]{2}{*}{ Characteristic } & \multicolumn{3}{|c|}{16 Wk of Peginterferon Alfa-2a + Ribavirin } & \multicolumn{3}{|c|}{24 Wk of Peginterferon Alfa-2a + Ribavirin } \\
\hline & $\begin{array}{c}\text { Genotype } 2 \\
(N=372)\end{array}$ & $\begin{array}{c}\text { Genotype } 3 \\
(N=358)\end{array}$ & $\begin{array}{c}\text { Any Genotype } \\
(\mathrm{N}=732) \dagger\end{array}$ & $\begin{array}{c}\text { Genotype } 2 \\
(N=356)\end{array}$ & $\begin{array}{c}\text { Genotype } 3 \\
(N=369)\end{array}$ & $\begin{array}{c}\text { Any Genotype } \\
(\mathrm{N}=731) t\end{array}$ \\
\hline \multicolumn{7}{|l|}{ Sex - no. (\%) } \\
\hline Male & $224(60)$ & $224(63)$ & $448(61)$ & $213(60)$ & $243(66)$ & $461(63)$ \\
\hline Female & $148(40)$ & $134(37)$ & $284(39)$ & $143(40)$ & $126(34)$ & $270(37)$ \\
\hline Age $-y r$ & $49.5 \pm 9.2$ & $42.4 \pm 9.0$ & $46.0 \pm 9.8$ & $49.3 \pm 9.3$ & $42.1 \pm 9.4$ & $45.6 \pm 10.0$ \\
\hline Weight — kg & $84.2 \pm 19.8$ & $78.9 \pm 18.1$ & $81.5 \pm 19.2$ & $84.3 \pm 19.3$ & $79.1 \pm 17.5$ & $81.6 \pm 18.6$ \\
\hline Body-mass index & $28.7 \pm 5.8$ & $26.8 \pm 5.5$ & $27.8 \pm 5.7$ & $28.7 \pm 5.8$ & $26.6 \pm 5.1$ & $27.6 \pm 5.6$ \\
\hline \multicolumn{7}{|l|}{ Race or ethnic group - no. (\%) } \\
\hline White & $309(83)$ & $325(91)$ & $635(87)$ & $301(85)$ & $333(90)$ & $638(87)$ \\
\hline Black & $12(3)$ & $10(3)$ & $22(3)$ & $18(5)$ & $3(<1)$ & $21(3)$ \\
\hline Asian & $11(3)$ & $9(3)$ & $21(3)$ & $8(2)$ & $8(2)$ & $18(2)$ \\
\hline Other & $40(11)$ & $14(4)$ & $54(7)$ & $29(8)$ & $25(7)$ & $54(7)$ \\
\hline \multicolumn{7}{|l|}{ Serum HCV RNA level } \\
\hline Mean $\pm S D-\log I U / m l$ & $6.38 \pm 0.85$ & $6.15 \pm 0.88$ & $6.27 \pm 0.87$ & $6.40 \pm 0.87$ & $6.15 \pm 0.80$ & $6.27 \pm 0.85$ \\
\hline$\leq 400,000 \mathrm{IU} / \mathrm{ml}-$ no. (\%) & $63(17)$ & $97(27)$ & $160(22)$ & $55(15)$ & $91(25)$ & $147(20)$ \\
\hline$>400,000-800,000 \mathrm{IU} / \mathrm{ml}-$ no. (\%) & $19(5)$ & $45(13)$ & $64(9)$ & $34(10)$ & $46(12)$ & $81(11)$ \\
\hline$>800,000 \mathrm{IU} / \mathrm{ml}$ - no. $(\%)$ & $290(78)$ & $216(60)$ & $508(69)$ & $267(75)$ & $232(63)$ & $503(69)$ \\
\hline Bridging fibrosis or cirrhosis — no. (\%) & $103(28)$ & $81(23)$ & $185(25)$ & $90(25)$ & $75(20)$ & $165(23)$ \\
\hline \multicolumn{7}{|l|}{ Steatosis - no. (\%) } \\
\hline None & $97(26)$ & $50(14)$ & $147(20)$ & $98(28)$ & $58(16)$ & $157(21)$ \\
\hline$>0-5 \%$ of hepatocytes & $101(27)$ & $90(25)$ & $191(26)$ & $94(26)$ & $85(23)$ & $181(25)$ \\
\hline $6-33 \%$ of hepatocytes & $30(8)$ & $58(16)$ & $88(12)$ & $22(6)$ & $66(18)$ & $89(12)$ \\
\hline $34-66 \%$ of hepatocytes & $11(3)$ & $41(11)$ & $53(7)$ & $13(4)$ & $39(11)$ & $52(7)$ \\
\hline$>66 \%$ of hepatocytes & $3(<1)$ & $10(3)$ & $13(2)$ & 0 & $4(1)$ & $4(<1)$ \\
\hline Unknown & $130(35)$ & $109(30)$ & $240(33)$ & $129(36)$ & $117(32)$ & $248(34)$ \\
\hline
\end{tabular}

* Plus-minus values are means \pm SD. Data are from the intention-to-treat population (all patients who received at least one dose of study medication). The body-mass index is the weight in kilograms divided by the square of the height in meters. Race or ethnic group was selfreported. Liver biopsy was performed within 24 months before the start of the study, and specimens were assessed by local pathologists for histologic status and were reviewed by one central pathologist, who was unaware of group assignment, for steatosis. Pretreatment assessments of liver steatosis were available for only approximately two thirds of patients. Steatosis was defined on the basis of the percentage of hepatocytes with fatty changes in one low-power field. The presence or absence of bridging fibrosis or cirrhosis could not be determined for one patient in the 24-week group.

$\dagger$ In addition to patients with HCV genotype 2 or 3 monoinfection, the overall group receiving treatment for 16 weeks included two patients infected with both HCV genotypes 2 and 4.

$\uparrow \mathrm{In}$ addition to patients with HCV genotype 2 or 3 monoinfection, the overall group receiving treatment for 24 weeks included four patients infected with both HCV genotypes 2 and 4, one with HCV genotype 1 only, and one with both HCV genotypes 1 and 2 .

tions in the dose of peginterferon alfa-2a to $135 \mu \mathrm{g}$ per week and then to $90 \mu \mathrm{g}$ per week, and stepwise reductions in the dose of ribavirin to $600 \mathrm{mg}$ per day, were permitted, to manage clinically significant adverse events or laboratory abnormalities. Restoration of the initial doses was permitted at the discretion of the investigator if the adverse event or laboratory abnormality improved or resolved. Patients could receive peginterferon alfa-2a alone if ribavirin was stopped, but study treatment was discontinued if peginterferon alfa-2a was stopped. The use of granulocyte colony-stimulating factor and erythropoietin was permitted but not encouraged. 


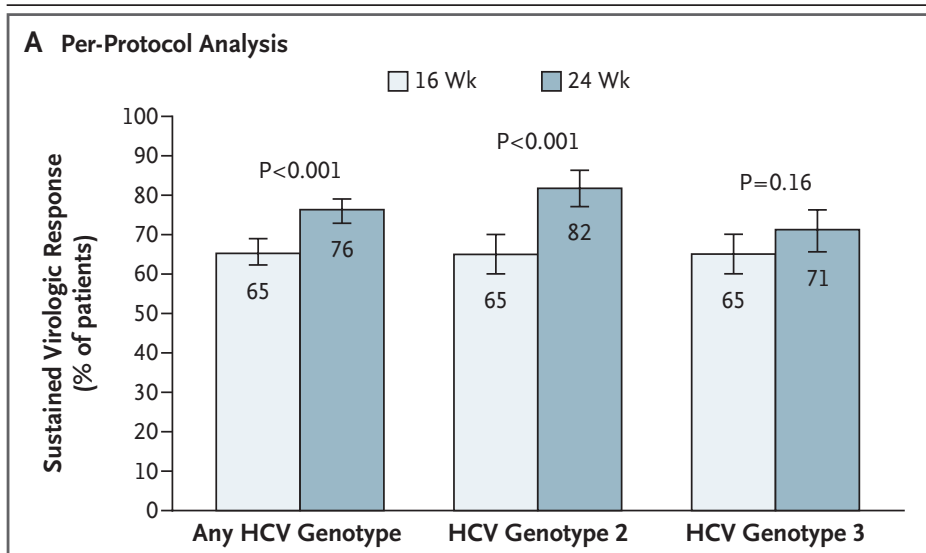

B Modified Intention-to-Treat Analysis

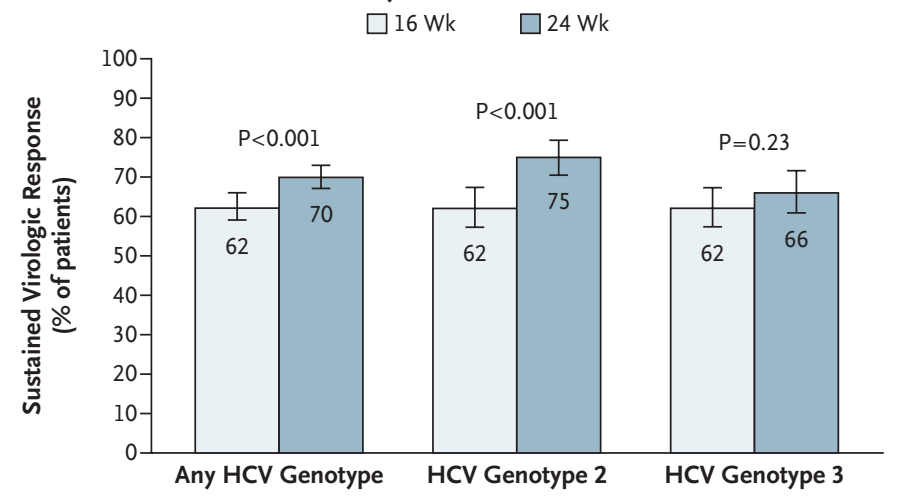

Figure 2. Rates of Sustained Virologic Response in Patients Randomly Assigned to Receive Treatment for $\mathbf{1 6}$ or $\mathbf{2 4}$ Weeks in the Per-Protocol Analysis and the Modified Intention-to-Treat Analysis.

A sustained virologic response was defined as an undetectable serum HCV RNA level (<50 IU per milliliter) at 24 weeks after the end of treatment. In addition to patients who were withdrawn early, those who received less than $80 \%$ of the planned doses of either study drug were excluded from the per-protocol population. I bars indicate $95 \%$ confidence intervals.

\section{STATISTICAL ANALYSIS}

The primary analysis was based on data from the per-protocol population, according to guidelines of the International Conference on Harmonisation of Technical Requirements for Registration of Pharmaceuticals for Human Use, because it is considered to be more a conservative means of analysis in a noninferiority trial. A modified intention-to-treat analysis was also performed, because it is considered to be a more stringent means of measuring overall efficacy and tolerability and it includes data from all patients who were randomly assigned to a treatment group and who received at least one dose of study medication. Moreover, when intention-to-treat and per-proto- col analyses lead to essentially the same conclusions, confidence in the trial results is increased. Patients for whom HCV RNA levels had not been measured by the end of the follow-up period were considered to have had treatment failure.

Our primary objective was to show that treatment for 16 weeks was no worse than treatment for 24 weeks, as defined by a noninferiority margin of $6 \%$. Response rates at the end of the treatment period and sustained virologic response rates in the two treatment groups were compared with the use of the Cochran-Mantel-Haenszel test (after data were stratified according to country of residence and HCV genotype). The common odds ratios and $95 \%$ confidence intervals were estimated. The interaction of treatment group and HCV genotype was assessed with the use of the Breslow-Day test, with data stratified according to genotype. The noninferiority margin was converted from $6 \%$ to an odds ratio of 0.70 by assuming a sustained virologic response rate of $80 \%$ in the 24-week group. On this basis, the 16week and 24-week regimens would be considered equivalent if the lower limit of the $95 \%$ confidence interval for the odds ratio was at least 0.70 . The planned enrollment of 700 patients per treatment group assumed a sustained virologic response rate of $80 \%$ in both groups, a statistical power of the study of $80 \%$, and a two-sided significance level of 0.05 .

The safety analysis included data from all treated patients who underwent safety evaluations during the treatment period. Stepwise, backward, and multiple logistic-regression analyses were used to examine the effect of treatment duration and pretreatment factors on the sustained virologic response. There was evidence of an interaction between treatment group and genotype $(\mathrm{P}=0.06)$, so separate analyses were performed according to genotype. The Cochran-MantelHaenszel test was conducted on data stratified on the basis of country of residence. Data were not stratified for other subgroup analyses. P values were two-sided and were not adjusted for multiple testing.

\section{RESULTS}

Of 1810 patients screened, 1469 were randomly assigned to a treatment group and 1465 received at least one dose of medication (Fig. 1). The two treatment groups were well matched (Table 1). 
Figure 3. Virologic Response Rates during the Treatment and Follow-up Periods in Patients Randomly Assigned to Receive Treatment for $\mathbf{1 6}$ or $\mathbf{2 4}$ Weeks.

$A$ rapid virologic response was defined as an undetectable serum HCV RNA level ( $<50$ IU per milliliter) by week 4 . An early virologic response was defined as an undetectable HCV RNA level, or a decrease in the HCV RNA level by more than $2 \log _{10}$ units from the pretreatment value, by week 12 . A sustained virologic response was defined as an undetectable serum HCV RNA level at 24 weeks after the end of treatment. The overall data for sustained virologic response are given for patients infected with only HCV genotype 2 or 3 plus two patients with both HCV genotypes 2 and 4 in the 16 -week group and four patients with both HCV genotypes 2 and 4, one with HCV genotype 1 only, and one with both HCV genotypes 1 and 2 in the 24 -week group.

\section{VIROLOGIC RESPONSE}

The results failed to show noninferiority of the 16-week regimen relative to the 24 -week regimen in both the per-protocol and the modified intentionto-treat analyses. Indeed, both analyses showed a similar pattern in the sustained virologic response rate among all patients, which was significantly lower in patients treated for 16 weeks than in those treated for 24 weeks in the per-protocol analysis (65\% vs. $76 \%$; odds ratio for 16 weeks vs. 24 weeks, $0.59 ; 95 \%$ confidence interval [CI], 0.46 to 0.76 ; $\mathrm{P}<0.001$ ) (Fig. $2 \mathrm{~A}$ ) and in the modified intention-to-treat analysis $(62 \%$ vs. $70 \%$; odds ratio, $0.67 ; 95 \% \mathrm{CI}, 0.54$ to 0.84 ; $\mathrm{P}<0.001$ ) (Fig. 2B). All subsequent analyses were done on data from the modified intention-to-treat population.

The virologic response rate at the end of the treatment period was significantly higher in the 16-week group than in the 24-week group (odds ratio for 16 weeks vs. 24 weeks, 1.82; 95\% CI, 1.35 to 2.47), because more patients in the 24-week group were withdrawn prematurely and were considered not to have had a response. Thus, the significant difference in the sustained virologic response rate reflects a significantly higher relapse rate in the 16-week group (31\%; 95\% CI, 27 to 34) than in the 24-week group (18\%; 95\% CI, 15 to 21; P<0.001) (Fig. 3).

Patients infected with HCV genotype 2 had higher virologic response rates at the end of treatment and at the end of follow-up than did patients with HCV genotype 3 (Fig. 3). Within each genotype group, relapse rates were significantly higher among patients treated for 16 weeks than

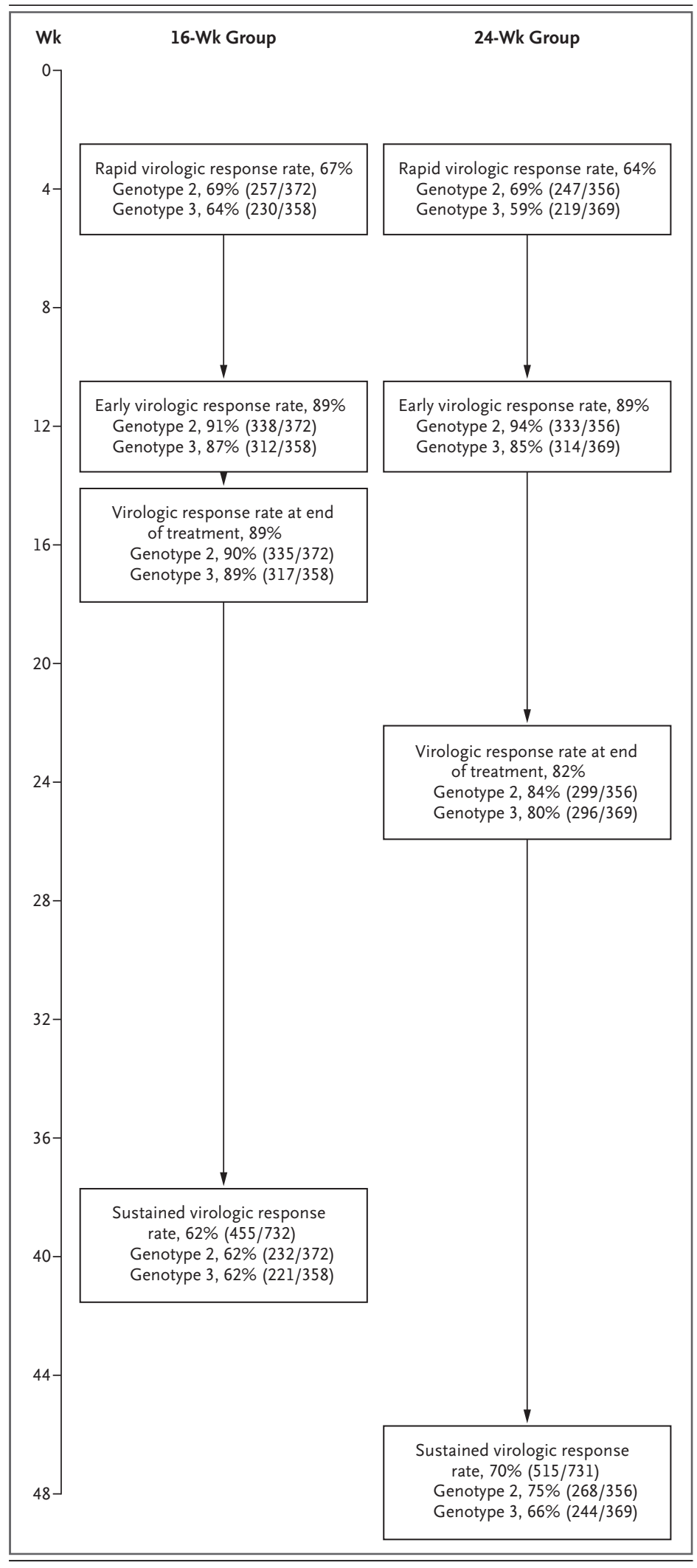


among those treated for 24 weeks (for genotype 2, $30 \%$ vs. $15 \%$; for genotype $3,31 \%$ vs. $22 \%$; $\mathrm{P}<0.001$ for both comparisons).

\section{PREDICTORS OF SUSTAINED VIROLOGIC RESPONSE}

Prespecified stepwise, backward, and multiple logistic-regression analyses showed that several factors were predictive of sustained virologic response: HCV genotype (odds ratio among patients with genotype 2 vs. genotype 3, 1.88; 95\% CI, 1.46 to 2.43; $\mathrm{P}<0.001)$; pretreatment HCV RNA level (odds ratio for $\leq 400,000$ IU per milliliter vs. $>800,000$ IU per milliliter, 3.01; 95\% CI, 2.15 to 4.20; $\mathrm{P}<0.001$; and odds ratio for $>400,000$ to 800,000 IU per milliliter vs. $>800,000$ IU per milliliter, 1.64 ; $95 \% \mathrm{CI}, 1.10$ to 2.46 ; $\mathrm{P}=0.02$ ); age (odds ratio for $\leq 45$ years vs. $>45$ years, 1.50 ; $95 \%$ CI, 1.17 to 1.93; $\mathrm{P}=0.002$ ); weight (odds ratio for $\leq 80 \mathrm{~kg}$ vs. $>80 \mathrm{~kg}, 1.75 ; 95 \% \mathrm{CI}, 1.37$ to 2.24 ; $\mathrm{P}<0.001$ ), alanine aminotransferase quotient (the patient's alanine aminotransferase value divided by the upper limit of the normal range) (odds ratio for $>3$ vs. $\leq 3,1.47$; $95 \%$ CI, 1.14 to 1.90 ; $\mathrm{P}=0.003$ ); bridging fibrosis or cirrhosis (odds ratio for absence vs. presence, 2.15; 95\% CI, 1.63 to 2.81; $\mathrm{P}<0.001$ ), and treatment duration (odds ratio for 24 weeks vs. 16 weeks, 1.56; 95\% CI, 1.24 to 1.97; $\mathrm{P}<0.001)$.

Lower pretreatment HCV RNA level, lower weight, and absence of bridging fibrosis or cirrhosis were predictive of a sustained virologic response in separate analyses performed for patients with HCV genotype 2 and those with HCV genotype 3 ( $\mathrm{P}<0.01$ for all analyses). Treatment for 24 weeks predicted a sustained virologic response in patients infected with genotype 2 $(\mathrm{P}<0.001)$ but not in those infected with genotype $3(\mathrm{P}=0.12)$.

\section{SUBGROUP ANALYSES}

Subgroup analyses indicated that, with the possible exception of genotype, interactions between treatment duration and various factors were not significant (Fig. 4). The sustained virologic response rate was higher in patients with HCV genotype 2 and those with HCV genotype 3 treated for 24 weeks than in corresponding patients treated for 16 weeks, but the difference was significant only for patients with genotype 2 .

A rapid virologic response was achieved in $67 \%$ of patients in the 16-week group and in 64\% of
Figure 4 (facing page). Effect of Characteristics of Patients, before and during Treatment, on Sustained Virologic Response.

A sustained virologic response was defined as an undetectable serum HCV RNA level (<50 IU per milliliter) at 24 weeks after the end of treatment. Steatosis was defined as more than $5 \%$ of hepatocytes with fatty changes in one low-power field. A rapid virologic response was defined as an undetectable serum HCV RNA level by week 4 of treatment. The shaded area indicates odds ratios of at least 0.70 , the noninferiority margin, showing that the 16 -week group is at least as effective as the 24-week group. In addition to patients infected with HCV genotype 2 or 3, for the "all patients" and "any genotype" categories, the 16-week group included two patients with HCV genotypes 2 and 4, and the 24-week group included four patients with HCV genotypes 2 and 4 , one with HCV genotype 1 , and one with HCV genotypes 1 and 2. Pretreatment assessments of liver steatosis were available for only approximately two thirds of patients. The presence or absence of cirrhosis or bridging fibrosis could not be determined for one patient in the 24-week group.

patients in the 24-week group. Among the patients with a rapid virologic response, sustained virologic response rates were consistently higher in the 24-week group than in the 16-week group, both overall ( $85 \%$ vs. $79 \%, \mathrm{P}=0.02)$ and within each genotype group (Fig. 5A). Sustained virologic response rates were considerably lower among patients without a rapid virologic response than among those with a rapid response, and among those without a rapid response, sustained virologic response rates were consistently higher in the 24-week group than in the 16-week group (Fig. 5B).

\section{SAFETY}

The most common cause of dose modifications of peginterferon alfa-2a and ribavirin were neutropenia and anemia, respectively. The percentage of patients who had their dose of peginterferon alfa-2a reduced because of adverse events or laboratory abnormalities was similar in the 24-week group and the 16-week group (17\% and 14\%, respectively). In contrast, a higher percentage of patients in the 24-week group than in the 16week group had their dose of ribavirin reduced ( $23 \%$ vs. $17 \%, \mathrm{P}=0.01$ ).

The percentage of patients reporting adverse events or serious adverse events was similar in the two groups. The adverse events reported were those typical of interferon-based treatment, in- 


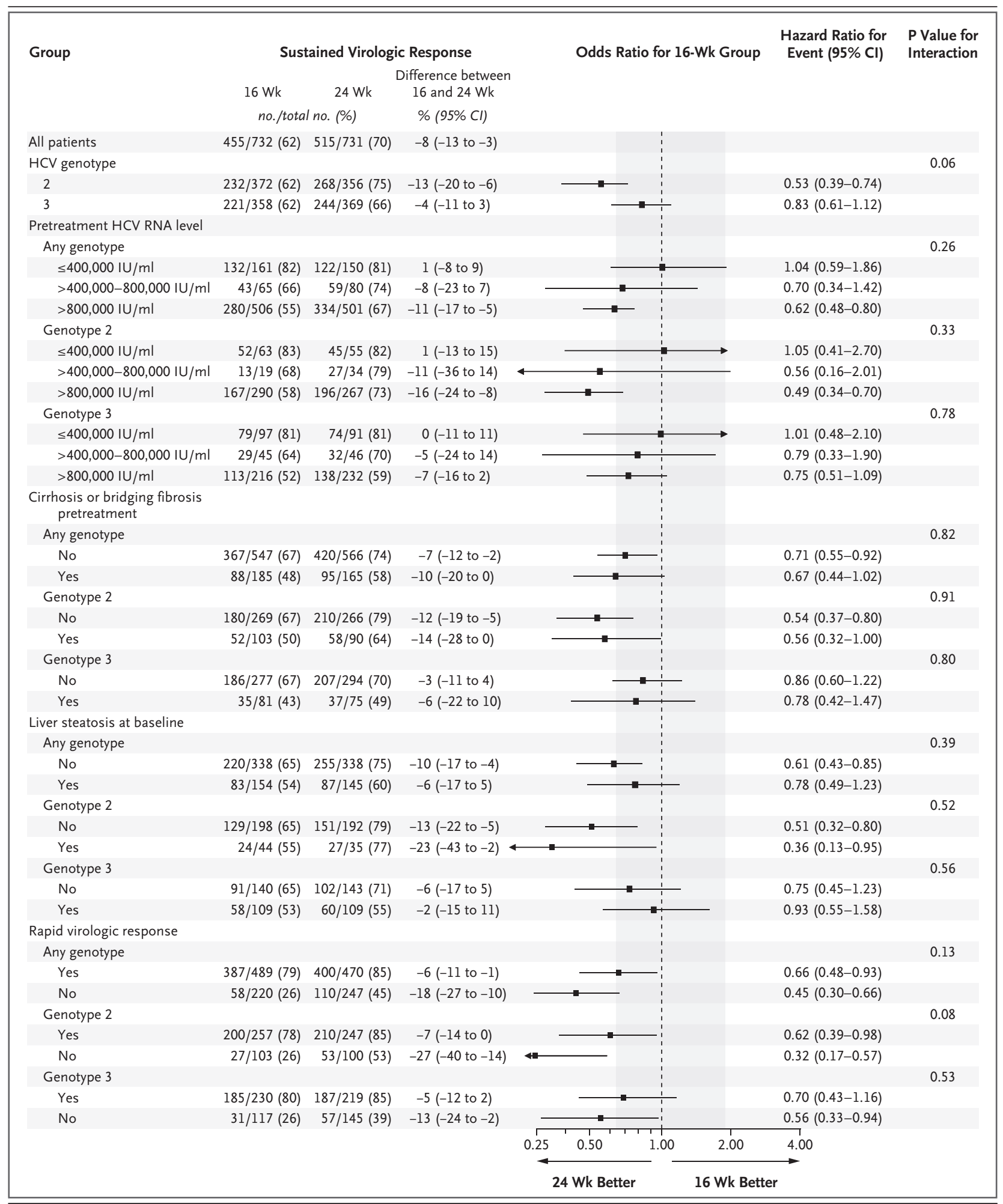




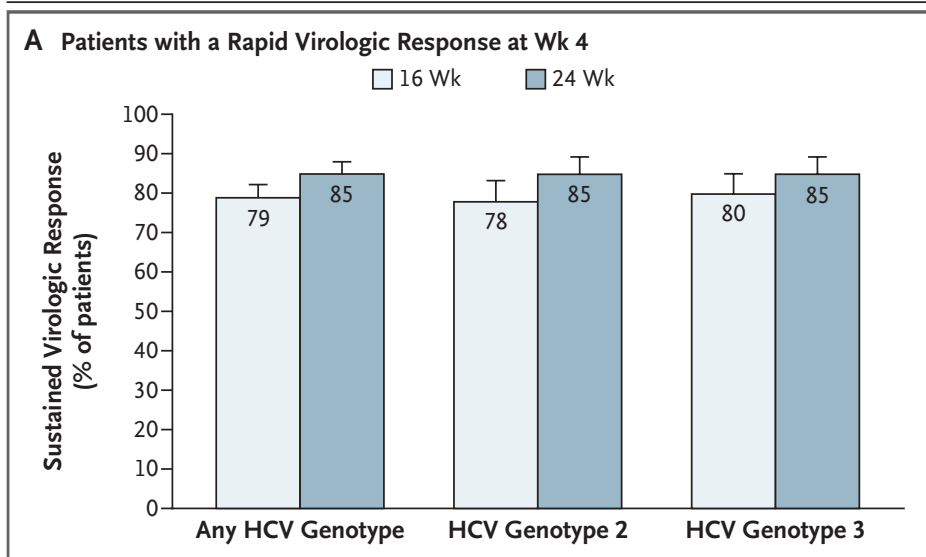

B Patients without a Rapid Virologic Response at Wk 4

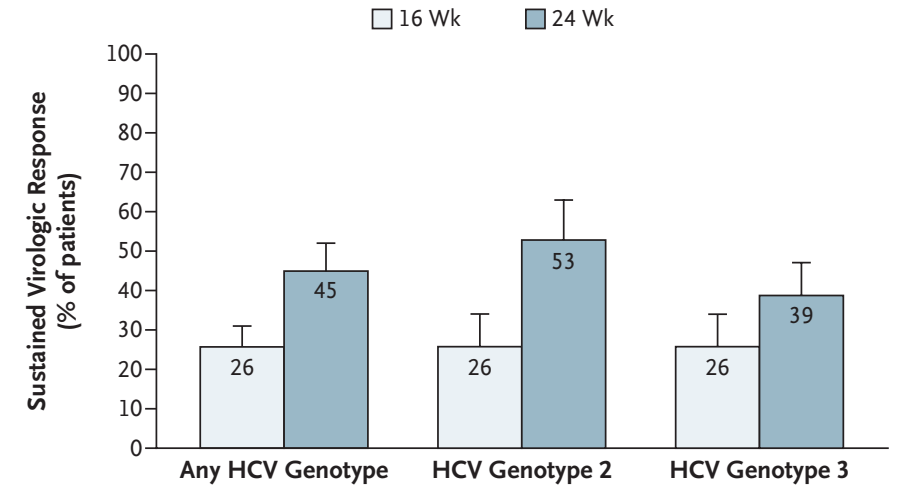

Figure 5. Rates of Sustained Virologic Response among Patients with and Those without a Rapid Virologic Response.

A sustained virologic response was defined as an undetectable serum HCV RNA level ( $<50$ IU per milliliter) at 24 weeks after the end of treatment. A rapid virologic response was defined as an undetectable serum HCV RNA level by week 4 of treatment. T bars indicate the upper bound of the $95 \%$ confidence interval. study during the first 16 weeks of therapy was similar in the two groups (Fig. 1). Overall, $4 \%$ of patients in the 16-week group and $5 \%$ of patients in the 24-week group were withdrawn because of adverse events or laboratory abnormalities.

DISCUSSION

Our large, randomized study of patients infected with HCV genotype 2 or 3 shows that a fixed 16week regimen of peginterferon alfa-2a plus ribavirin results in significantly lower sustained virologic response rates than does a fixed 24-week regimen. Consistent with the overall result, the odds ratios for a sustained virologic response favored 24 weeks of treatment over 16 weeks in many subgroups, a finding that suggests that the preferred initial duration of treatment for patients with genotype 2 or 3 should continue to be 24 weeks.

The results of several small studies suggest that treatment with pegylated interferon and ribavirin for 12 or 16 weeks, rather than 24 weeks, does not adversely affect sustained virologic response rates in patients with HCV genotype 2 or 3. ${ }^{4-6}$ In two such studies, ${ }^{5,6}$ patients treated for 24 weeks had somewhat lower virologic response rates at the end of the treatment period than did those receiving shorter regimens, presumably because of higher dropout rates with longer treatment. In contrast, relapse rates were somewhat higher with the shorter duration of treatment. As a result, the higher dropout rates in the 24week treatment groups were offset by the higher relapse rates in the shorter-treatment groups, resulting in the groups having similar sustained virologic response rates. This finding led many to conclude that a shorter regimen is as effective as the standard 24-week regimen. The intentionto-treat analysis of our data reveals the same pattern: higher dropout rates in the 24-week group and higher relapse rates in the 16-week group. Response rates at the end of the treatment period were similar (within 3\%; data not shown) in the two groups, according to the per-protocol analysis. This similarity, in addition to our large sample size, shows that reducing the treatment duration from 24 to 16 weeks results in increased relapse rates and therefore reduced sustained virologic response rates. 
The customization of the duration of therapy is an emerging theme in the management of chronic HCV., ${ }^{5,-11}$ In patients infected with genotype 2 or 3, a variable treatment regimen (12 weeks in patients with a rapid virologic response and 24 weeks in those without a rapid virologic response) resulted in a sustained virologic response rate $(77 \%)$ similar to that from a standard 24 week regimen (76\%). ${ }^{5}$ Our study was not designed to evaluate this treatment approach, but our results shed light on its validity. Overall, $66 \%$ of patients with HCV genotype 2 or 3 had rapid virologic responses in our study, a figure similar to that found by Mangia et al. (63\%). ${ }^{5}$ The sustained virologic response rate among patients with a rapid virologic response treated for 16 weeks and those without a rapid virologic response treated for 24 weeks - a population similar to the variable-duration group in the study by Mangia et al. - was $68 \%$, similar to the $70 \%$ rate in our fixed 24-week group. A variable-duration treatment strategy may therefore be as effective as a fixed-duration strategy and may be less expensive for and better tolerated by the majority of patients. The trade-off in reducing the treatment duration is an increased relapse rate, which was observed in our study and in other studies. ${ }^{4-6}$ Thus, the reduction of the treatment duration, even in patients with rapid virologic responses, is likely to be accompanied by higher relapse rates and the need to consider retreatment for these patients.

Could higher doses of ribavirin prevent relapse after treatment for less than 24 weeks? In previous studies, treatment for 24 weeks with ribavirin (with the dose based on body weight) provided no benefit over the recommended ribavirin dose of $800 \mathrm{mg}$ per day in patients infected with HCV genotype 2 or $3^{2,12}$ In fact, one study ${ }^{13}$ has suggested that it may be possible to reduce the ribavirin dose to $400 \mathrm{mg}$ per day without compromising the efficacy of the standard 24-week regimen. Ribavirin doses as high as $1200 \mathrm{mg}$ per day, which have been used in studies evaluating reduced durations of therapy, ${ }^{5-7}$ appear to offer no obvious benefit in reducing the relapse rate. However, further study is needed to confirm the optimal dose of ribavirin for abbreviated treatment regimens.

Sustained virologic response rates decrease in inverse proportion to pretreatment viral load. ${ }^{2,3,14}$ Among patients with a pretreatment viral load of 400,000 IU per milliliter or less in our study, the sustained virologic response rate was $1 \%$ higher in the 16-week group than in the 24-week group. Among those with a pretreatment viral load of more than 400,000 IU per milliliter, the difference was $11 \%$, in favor of the 24 -week regimen. Patients with low pretreatment viral loads or rapid virologic responses have the highest likelihood ( $>78 \%$ ) of a sustained virologic response with 16 weeks of therapy. Reduced durations of therapy may also be reasonable in patients who have adverse events and are unlikely to tolerate 24 weeks of therapy. The decision to reduce the duration of treatment must be balanced against the increased risk of relapse. Patients who do not have a rapid virologic response should not be considered easy to cure and should not be offered abbreviated treatment.

In conclusion, our study shows that a fixed 16-week regimen is inferior to a fixed 24-week regimen in patients with HCV genotype 2 or 3 . These patients should not be routinely treated for less than the currently recommended 24 weeks. However, patients with a low pretreatment viral load or a rapid virologic response appear to have the highest probability of having a sustained response with 16 weeks of therapy, and such therapy may be a reasonable option for these patients.

\section{Supported by Roche.}

Dr. Shiffman reports receiving consulting fees from Roche, lecture fees from Roche and Schering-Plough, and grant support from Roche, Schering-Plough, Vertex Pharmaceuticals, Valeant, Coley Pharmaceuticals, Gilead Sciences, and GlaxoSmithKline; Drs. Suter and Nelson, consulting and lecture fees and grant support from Roche; Dr. Bacon, consulting fees from ScheringPlough, Coley Pharmaceuticals, Intermune, and Valeant, lecture fees from Schering-Plough and Gilead, and grant support from Roche, Schering-Plough, Gilead, GlaxoSmithKline, Intermune, and Valeant; Dr. Harley, consulting fees from Roche and ScheringPlough and lecture fees from Schering-Plough; Dr. Solá, lecture fees from Roche; Dr. Shafran, consulting and lecture fees from Roche and Schering-Plough and grant support from Roche, Schering-Plough, and Valeant; and Dr. Zeuzem, consulting fees from Roche, Schering-Plough, and Human Genome Sciences, lecture fees from Roche and Schering-Plough, and being a clinical investigator for Roche. Ms. Lin and Dr. Soman report being employees of Roche. No other potential conflict of interest relevant to this article was reported.

We thank Dr. Sugantha Govindarajan at the Liver Research Laboratory for assessing the degree of steatosis in the liverbiopsy specimens; Dr. Greg Hooper, a clinical scientist at Roche, for his assistance throughout the study; and Dr. Patrick Hoggard at Wolters Kluwer Health for his assistance in medical writing (funded by Roche). 


\section{APPENDIX}

In addition to the authors, the following investigators participated in the ACCELERATE study: Australia - D. Crawford, L. Leggett, S. Roberts, M. Weltman; Canada - S. Greenbloom, K. Menon; France - M. Bourliere, P. Brissot, J.-P. Bronowicki, M. Doffoël, C. Hézode, P. Marcellin, A. Tran, J.-P. Zarski; Germany - O. Avci, T. Berg, O. Potthoff, J. Rasenack, O. Ross, M. von Wagner; Italy — A. Ascione, S. Brillanti, M. Brunetto, R. Bruno, S. Bruno; New Zealand - E. Gane; Spain - J. Aguilar, R. Bárcena, M. Diago, J. Enríquez, J. García-Samaniego, R. Moreno, R. Planas, D. Rincón, R. Solá, M. Testillano; United States - B. Anand, B. Bahri Bilir, V. Balan, L. Bank, E. Barranco, C. Berg, D. Bernstein, J. Bloom, H. Bonkovsky, T. Box, N. Brau, N. Bzowej, W. Cassidy, D. Clain, J. Corasanti, M. Davis, E. DeJesus, P. Delich, S. Esposito, K. Etzkorn, K. Flora, M. Fried, H. Fromm, R. Ghalib, A. Gibas, E. Godofsky, S. Gompf, S. Gordon, F. Gordon, G. Hammoud, S. Harrison, J. Herrera, S. Ho, C. Howell, S. Joshi, E. Keeffe, K. Kranz, P. Kwo, G. LakeBakaar, A. Larson, A. Levin, A. Lok, M. Lucey, M. Lyons, P. Malet, P. Malik, R. Manch, S. Mehta, A. Mihas, D. Mikolich, T. Morgan, A. Muir, R. Nguyen, D. Nunes, L. Nyberg, C. O’Brien, S. Pappas, M. Pauly, M. Pedrosa, M. Perkel, J. Person, P. Pockros, A. Post, J. Poulos, R. Powell, V. Raj, A. Reed, R. Reindollar, T. Riley, M. Rodriguez-Torres, R. Rubin, G. Sahagun, W. Schmidt, T. Sepe, T. Shaw-Stiffel, A. Sheikh, K. Sherman, C. Smith, D. Stevens, M. Sulkowski, D. Toro, E. Torres, T. Tran, N. Tsai, R. Wohlman, W. Wright, L. Wruble, Z. Younossi.

\section{REFERENCES}

1. Strader DB, Wright T, Thomas DL, Seeff LB. Diagnosis, management, and treatment of hepatitis C. Hepatology 2004;39:114771. [Erratum, Hepatology 2004;40:269.]

2. Hadziyannis SJ, Sette H Jr, Morgan TR, et al. Peginterferon-alpha2a and ribavirin combination therapy in chronic hepatitis C: a randomized study of treatment duration and ribavirin dose. Ann Intern Med 2004;140:346-55.

3. Manns MP, McHutchison JG, Gordon SC, et al. Peginterferon alfa-2b plus ribavirin compared with interferon alfa- $2 \mathrm{~b}$ plus ribavirin for initial treatment of chronic hepatitis C: a randomised trial. Lancet 2001;358:958-65.

4. Dalgard O, Bjoro K, Hellum KB, et al. Treatment with pegylated interferon and ribavirin in HCV infection with genotype 2 or 3 for 14 weeks: a pilot study. Hepatology 2004;40:1260-5.

5. Mangia A, Santoro R, Minerva N, et al. Peginterferon alfa-2b and ribavirin for 12 vs. 24 weeks in HCV genotype 2 or 3 . N Engl J Med 2005;352:2609-17.
6. von Wagner M, Huber M, Berg T, et al. Peginterferon-alpha-2a (40KD) and ribavirin for 16 or 24 weeks in patients with genotype 2 or 3 chronic hepatitis C. Gastroenterology 2005;129:522-7.

7. Yu ML, Dai CY, Huang JF, et al. A randomised study of peginterferon and ribavirin for 16 versus 24 weeks in patients with genotype 2 chronic hepatitis C. Gut 2007;56:553-9.

8. Henry MJ. Peginterferon alfa-2b and ribavirin for 12 versus 24 weeks in HCV infection. N Engl J Med 2005;353:1183.

9. Jensen DM, Morgan TR, Marcellin P, et al. Early identification of HCV genotype 1 patients responding to 24 weeks peginterferon alpha-2a $(40 \mathrm{kd}) /$ ribavirin therapy. Hepatology 2006;43:954-60. [Erratum, Hepatology 2006;43:1410.]

10. Zeuzem S, Buti M, Ferenci P, et al. Efficacy of 24 weeks treatment with peginterferon alfa-2b plus ribavirin in patients with chronic hepatitis $\mathrm{C}$ infected with genotype 1 and low pretreatment viremia. J Hepatol 2006;44:97-103.
11. Ferenci P, Bergholz U, Laferl H, et al. 24 Week treatment regimen with peginterferon alpha-2a (40KD) (Pegasys) plus ribavirin (Copegus) in HCV genotype 1 or 4 'super-responders.' J Hepatol 2006;44: Suppl 2:S6. abstract.

12. Jacobson I, Brown R, Freilich B, et al. Weight-based ribavirin dosing (WBD) increases sustained viral response (SVR) in patients with chronic hepatitis $\mathrm{C}$ (CHC): final results of the WIN-R Study, a US community based trial. Hepatology 2005; 42:Suppl 1:749A. abstract.

13. Ferenci $\mathrm{P}$, Brunner $\mathrm{H}$, Laferl $\mathrm{H}$, et al. Further reduction of ribavirin dose in HCV genotype 2/3 patients receiving peginterferon alfa-2a (40KD) (Pegasys) plus ribavirin (Copegus): interim results of a randomised controlled trial. J Hepatol 2006; 44:Suppl 1:S37. abstract.

14. Fried MW, Shiffman ML, Reddy KR, et al. Peginterferon alfa-2a plus ribavirin for chronic hepatitis $\mathrm{C}$ virus infection. N Engl J Med 2002;347:975-82.

Copyright (c) 2007 Massachusetts Medical Society.

FULL TEXT OF ALL JOURNAL ARTICLES ON THE WORLD WIDE WEB

Access to the complete text of the Journal on the Internet is free to all subscribers. To use this Web site, subscribers should go to the Journal's home page (www.nejm.org) and register by entering their names and subscriber numbers as they appear on their mailing labels. After this one-time registration, subscribers can use their passwords to log on for electronic access to the entire Journal from any computer that is connected to the Internet. Features include a library of all issues since January 1993 and abstracts since January 1975, a full-text search capacity, and a personal archive for saving articles and search results of interest. All articles can be printed in a format that is virtually identical to that of the typeset pages. Beginning 6 months after publication, the full text of all Original Articles and Special Articles is available free to nonsubscribers who have completed a brief registration. 